\title{
Current Status of CCS Technology for Reducing Greenhouse Gases in Coal-Fired Power Plants
}

\author{
Jiyoung Kim, Hee Jung Kim, Ji Ye Yoo, and Chan Jin Park
}

\begin{abstract}
Recent increase of greenhouse gas has been serious in recent years. The status and problems of coal-fired power plants in Korea and discussions about reducing greenhouse gases emitted from coal-fired thermal power plants were investigated. The policy of power plants that would replace coal-fired thermal power plants and reduce greenhouse gases were studied. The current status of CCS and the methods about our environmental policy to solve global warming problems in Korea were suggested.
\end{abstract}

Index Terms-Carbon dioxide, coal-fired power plants, carbon capture and storage.

\section{INTRODUCTION}

Coal is an important source of energy for domestic development, but it is not efficient when considering climate change, air pollution and water pollution, and environmental pollution, such as climate change and water pollution [1]. During the combustion process, pollutants such as nitrogen oxides, sulfur oxides, carbon dioxide and fine dust are emitted particularly in the most recent serious problems of microfilament. $\mathrm{PM}_{2.5}$ accounts for 3.4 percent of the total amount of coal fired power plants. The particulate matter produced here generates a second generation of microscopic particulates (41 percent) and a wide range of chemical reactions from the chemical reactions of sulfur dioxide and emitted from coal fired plants. Since $41 \%$ of the ultra-crafted particulates are secondary dust generation, they should focus on the effects of atmospheric pollution in the long run, leaving a large amount of ultrafine dust emitted by the coal-fired steam power plant. Therefore, it is also planning to shut down the decrepit plant as a result of the recent measures concerning plant issues related with dust pollution [1].

According to a report released by the IPCC in 2013, the governmentshouldreducegreenhousegasemissionsby40to 70

Manuscript received September 18, 2017; revised July 12, 2018. This work was supported by Korea Ministry of Environment (MOE) as $\ulcorner$ Knowledge-based environmental service Human resource development Project $\lrcorner$.

Ji Young Kim is with the Department of Energy and Environment Engineering, Incheon National University, Republic of Korea (e-mail: jiyoungK@inu.ac.kr).

Hee Jung Kim was with the Department of Energy and Env. Engineering, Incheon National University, Republic of Korea (e-mail: kimheejung@inu.ac.kr).

Ji Ye Yoo is with the Department of Climate International Cooperation, Incheon National University, Republic of Korea (e-mail: yoojiye@inu.ac.kr).

Chan Jin Park is with the Department of Energy and Env. Engineering and the Department of Climate International Cooperation, Incheon National University, Republic of Korea (corresponding author: Chan Jin Park; e-mail: cjpark@inu.ac.kr). percent, including carbon dioxide, by 2050. Coal is the largest single emitter of carbon dioxide emitted by fossil fuels worldwide, with the largest amount of coal burning. As coal plays an important role in the domestic development, it should also take up counter measures for greenhouse gases that occur as well. Therefore, we would like to study carbon dioxide capture and storage technologies that can effectively reduce the anthropogenic greenhouse gases [1].

\section{A STUDY ON THE PROBLEMS AND REDUCTION TECHNOLOGIES OF COAL-FIRED POWER PLANTS}

\section{A. Status of Domestic Coal Fired Power Plants}

Since the 1960s, South Korea has used coal as its main source of energy. The consumption of coal continued to increase as coal was first used to develop bituminous coal. Since then, oil, LNG, and nuclear power have grown to become a major source of energy, and coal accounts for 29 percent of the total energy supply in 2012 [1].

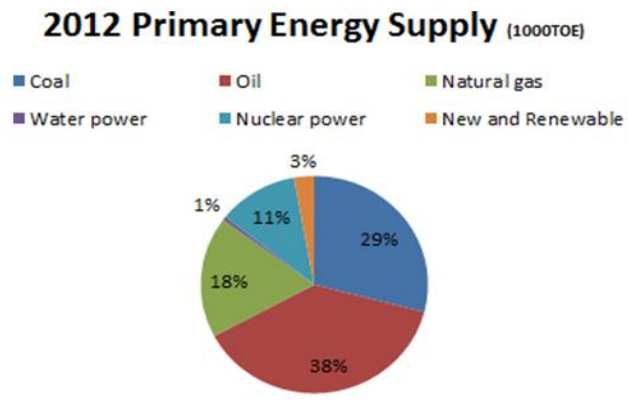

Fig. 1. 2012 Primary energy supply [1].

Fig. 1 shows that the nation's capacity for generating electricity is 29 percent in 2014 and a total of 53 coal fired coal-fired plants operating in Korea. It currently accounts for 67percent of the total population in South Chungcheong Province and Incheon, and is currently planning to build 11 more units by 2020 and plans to build 13 more units by 2020 . Korea's coal imports are the world's fourth-largest foreign-run coal reserves, with coal imported mostly at 67 percent for the most advanced coal reserves [1].

\section{B. Problems of Coal Fired Power Plants}

Coal is an important source of energy for domestic development, but there are many problems arising from mining, burning and processing of coal. The IPCC announced that it would reduce greenhouse gas emissions by 40 to 70 percent, including carbon dioxide, to reduce the Earth's $\mathrm{CO}_{2}$ emissions. Carbon dioxide $\left(\mathrm{CO}_{2}\right)$, the highest concentration of greenhouse gases is emitted by the use of fossil energy, 
such as coal and petroleum, to reduce emissions through direct reductions. In order to reduce global warming caused by greenhouse gases, CCS technology is gaining steam in ways to reduce carbon dioxide. Prior to the discovery of carbon dioxide, it is characterized by a technique that can save 20 percent of the total carbon dioxide emissions in the ground or in the oceans, stored in the ground or in the oceans safely.

\section{Alternative Technologies for Coal-Fired Power Plants}

1) Ultra Super Critical Plants

Highly efficient power generation plants benefit from controlling high temperatures, reducing $\mathrm{CO} 2$ emissions and other GHGs emissions during long periods of time lowering greenhouse gas emissions. Fig. 2 shows the USC process. However, it is impossible to replace existing boilers because it is a technology that greatly increases the state of coal fired power plants. Therefore, it is possible to apply only new plants or to abolish and implement decrepit plants [2].

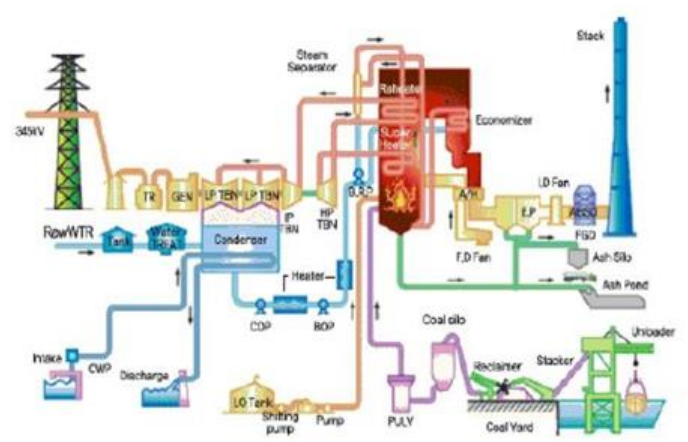

Fig. 2. USC process drawing [2].

\section{2) Circulating Fluidized Bed Generator}

A circulating fluidized bed generator is a technique that overcomes the disadvantages of coal fired combustion techniques, a traditional coal fired power generation technique. It is the method of supplying coal to a burning furnace composed of sand and ash, and the rapid injection of the particles through the bottom of the furnace to circulate the particles in the suspended solids. It is possible to inject dehumidification agents directly into the combustion furnace, allowing them to deconstruct and remove more than $95 \%$ of sulfur oxides [2].

3) Integrated Gasification combinedcycle

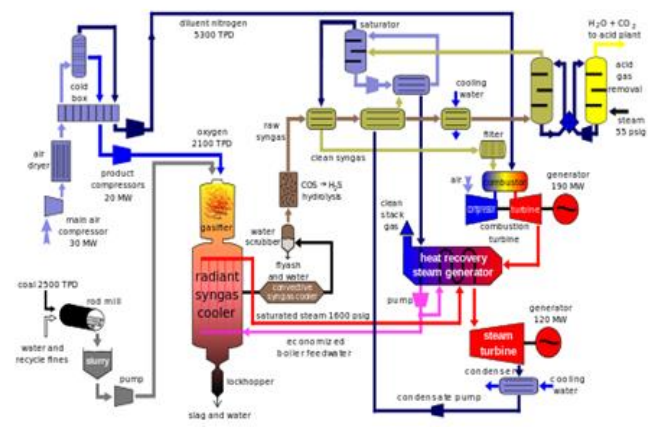

Fig. 3. IGCC process drawing [2].

Integrated Gasification combined cycle technology is a composite power generation system that uses coal gasification technology to fuel coal, carbon monoxide and hydrogen and gas turbines and steam turbines to drive gas-power turbines and steam turbines. The IGCC process is Fig. 3. High efficiency facilities reduce emissions of pollutants such as $\mathrm{CO}_{2}, \mathrm{NOx}$, $\mathrm{SOx}$, and fine dust. Further, the technology can capture $\mathrm{CO}_{2}$ technology by applying pre-combustion capture method to reduce compression costs by separating $\mathrm{CO}_{2}$ at high pressure levels, resulting in $\mathrm{CO}_{2}$ separation relatively easier than the capturing $\mathrm{CO}_{2}$ collection technique [2].

\section{Carbon Capture and Storage, CCS}

Carbon capture and storage technology captures carbon dioxide from large quantities of carbon dioxide generation, such as coal fired power plants, steel and cement plants, and compresses and transports them to underground or marine deposits [2].

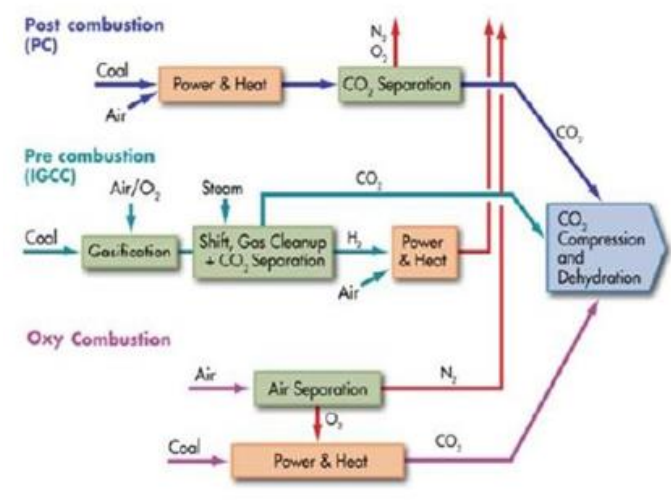

Fig. 4.CCS process drawing [2].

Fig. 4 shows that CCS technology is a technique that captures and compresses large quantities of carbon dioxide in industrial processes, such as plants and steel, and stores them safely and securely in land or sea. That is, it uses fossil fuels, and isolates carbon dioxide from the process without releasing it into the atmosphere. (IEA)

\section{Advantages}

- May retain coal fired method.

- The contribution of various technologies to reduce $\mathrm{CO} 2$ is expected to be effective.

- Expand into a clean development system (CDM) project to provide business benefits besides environmental benefits.

- $20 \%$ contributiontoreducingcarbondioxideemissions

- 80to90\%lowerthantheamountofcarbondioxideemitted by atmospheric emission weak point.

Disadvantages

- Massive installation size and expensive costs.

- Although the collection, transport and storage techniques comprising the CCS technology have been independently verified, the commercialization of the processes with the integration of the three technologies has not yet been achieved.

Whether carbon dioxide can be stored permanently underground or underground storage is uncertainty of the risk of being affected by the earthquake.

1) Pre-combustioncapture

It is a process technology that does not generate carbon dioxide through combustion and separates the fossil fuel used in the plant into hydrogen and carbon dioxide gas mixture, burns hydrogen, compresses carbon dioxide, and stores it. Table $\mathrm{I}$ is advantages and disadvantages of pre-combustion capture. 
TABLE I: ADVANTAGES AND DISADVANTAGES OF PRE-COMBUSTION CAPTURE

\begin{tabular}{|c|c|c|}
\hline & Advantages & Disadvantages \\
\hline Pre-combustio & $\begin{array}{lll}\text { Lower facility } & \text { size } \\
\text { due to high } \\
\text { temperatures and }\end{array}$ & $\begin{array}{l}\text { Difficult to adapt to } \\
\text { existing }\end{array}$ \\
\hline n capture & $\begin{array}{l}\text { high pressure } \\
\text { conditions. }\end{array}$ & $\begin{array}{l}\text { requiring changes in the } \\
\text { design phase. }\end{array}$ \\
\hline
\end{tabular}

2) Post-combustioncapture

Technology for absorbing and separating carbon dioxide by using absorbent, adsorbent and separation membrane

Like a Table II, post-combustion capture can operation at atmospheric pressure and low temperature. But expensive and need to remove impurities before collection.

TABLE II: ADVANTAGES AND DisADVANTAGES OF PRE-COMBUSTION

\begin{tabular}{|c|c|c|}
\hline \multicolumn{3}{|c|}{ CAPTURE } \\
\hline & Advantages & Disadvantages \\
\hline $\begin{array}{c}\text { Post-combustio } \\
\text { n capture }\end{array}$ & $\begin{array}{c}\text { Operation at } \\
\text { atmospheric pressure } \\
\text { and low temperature. } \\
\text { Relative to } \\
\text { commercialization. }\end{array}$ & $\begin{array}{c}\text { Expensive renewable } \\
\text { energy } \\
\text { Need to remove } \\
\text { impurities before } \\
\text { collection } \\
\text { Mass production of gas } \\
\text { requires additional } \\
\text { process. }\end{array}$ \\
\hline
\end{tabular}

3) Oxy-fuel combustioncapture

It is a technology for separating and recovering carbon dioxide and condensing water vapor in exhaust gas composed of water vapor and carbon dioxide after replacing air with pure oxygen and using it as an oxidizing agent.

It can capture high concentration of carbon dioxide and boasts a high recovery rate of about $100 \%$. The below Table III is advantages and disadvantages of oxy-fuel combustion capture.

TABLE III: ADVANTAGES AND DISADVANTAGES OF OXY-FUEL COMBUSTION CAPTURE

\begin{tabular}{ccc} 
& COMBUSTION CAPTURE & Disadvantages \\
\hline & Increase efficiency. & \\
Carbon dioxide & \\
Oxy-fuel & $\begin{array}{c}\text { concentration in the flue } \\
\text { gas is over } 80 \% \text {, so no } \\
\text { combustio }\end{array}$ & Oxygen is expensive to \\
n capture & technology is required & use \\
& for transportation and & \\
& storage. & \\
\hline
\end{tabular}

4) Ocean storage

Carbon dioxide is injected into the deep sea of 1000-3000m and dissolved or hydrated in seawater and stored. But it is currently forbidden.

5) Mineral carbonation

Technique to make carbonate mineral by reacting carbon dioxide with minerals containing magnesium or calcium and solidify it.

6) Geologicstorage

It is currently the most developed and applied technology to inject carbon dioxide into suitable space in inland or submarine stratum.

Fig. 5 shows that there are two main ways to reduce $\mathrm{CO} 2$ emissions from coal-fired power plants. By applying the technologies of the highest available electro-electronics technology, it minimizes the amount of carbon dioxide produced in the same electrical production, and the rest of the generation carbon dioxide is applied to achieve zero emission [3].

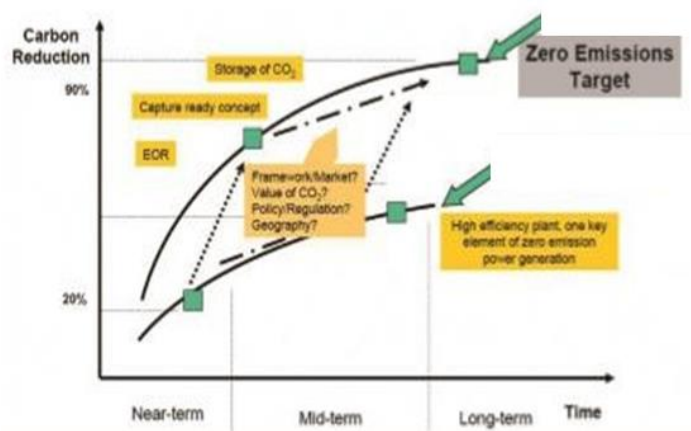

Fig. 5. Two techniques of removing $\mathrm{CO}_{2}$ from coal-fired power plants [3].

$\mathrm{CO}_{2}$ emissions from coal fired power plants produce approximately 3 million tons of $\mathrm{CO}_{2}$ per year in a 500MW. Although the technologies that produce natural gas and plastics are being developed, there is no substantial amount of $\mathrm{CO}_{2}$ that is actually used in the coal generation. In addition, the use of oil and natural gas is used for $\mathrm{CO}_{2}$, which turns out to be a large amount of carbon dioxide in the oil and natural gas reserves, which increases the amount of $\mathrm{CO}_{2}$ and natural gas reserves by 5 to 15 percent [3].

\section{E. Domestic CCS Trends and Problems in Korea}

Globally, carbon dioxide capture technology has developed a wide range of $R \& D$ technologies and development with verification projects. Advanced countries such as the United States and Japan are actively pursuing high technologies for developing large-scale technologies and reducing expenses to diminish expenses for CCS. The major developed countries recognize CCS as the core of greenhouse gas reduction and are competitively developing the next generation of technologies for supporting technologies [4].

In the United States, the company established a " National Carbon Capture Center (NCCC) " under the Ministry of Energy's Department of Energy for 17 years and is investing \$ 150 million. Japan is pushing for the development and development of the new industrial technology development agency (NEDO) and the Industrial Development Agency (RITE) and the Research and Development Agency (RITE). European plans to inject \$ 6 billion into six to 12 large-scale projects aimed at reaching 20 to 12 billion dollars for 20 years and zero emission of power plant $\mathrm{CO}_{2}$ emissions. Australia is the world's largest coal exporter, developing CCS technology as a national strategy. Norway has pioneered the world's first large-scale storage of $\mathrm{CO}_{2}$ since 1996 [4], [5].

In the case of our country, we are making various efforts to prepare for the new greenhouse gas reduction system in 2015 and to achieve greenhouse gas reduction targets submitted to the UN in 2015. In 2010, the government announced its plan to develop a TDS technology initiative by 2020 aiming to secure national GHG reduction measures by 2020 by announcing a comprehensive implementation plan for promoting national CCS and achieving global competitiveness of plants and technologies. Evidence of large-scale capture and storage integration is supported in accordance with 16 policy challenges in three areas: $R \& D$, promotion of commercialization, environmental management 
and foundation implementation. As Table IV shows that the major developed nations of the CCS technology have set up along-range goal of developing long-term mid-term CCS technology development strategies by 2020 , while the nation has failed to develop a long-range strategy and technology development strategy, which is a major stumbling block to the development of CCS technology and technology development strategies since 2020 [4], [5].

TABLE IV: LONG TERM GAS REDUCTION IN MAJOR NATION [4]

\begin{tabular}{ccc}
\hline Nation & Year & Goal \\
\hline America & 2005 & $83 \%$ reduction \\
EU & 1990 & $80 \sim 95 \%$ reduction \\
Japan & 2005 & $80 \%$ reduction \\
Russia & 1990 & $50 \%$ reduction \\
Canada & 2006 & $60 \sim 70 \%$ reduction \\
Korea & - & - \\
\hline
\end{tabular}

As demonstrated by the overall trends in the CCS sector in major economies, current CCS technology is proving to be feasible and practical, demonstrating the commercialization of the technology worldwide. However, the nation is experiencing a slow growth in the CCS sector due to problems such as uncertainty and lack of support. Thus, support for the acceleration of the large-scale collection and transportation of the current collection and green transportation project is needed. It is important to acquire a technological advantage by developing innovative technologies through innovative technologies to survive competition with major economies [4].

\section{CONCLUSION}

Carbon dioxide capture storage accounts for approximately $90 \%$ of the CCS technology, resulting in higher technical presentation. In the developed CCS advanced countries, CCS enhanced the utilization of CCS as a means of reducing GHG emissions, increasing the utilization of the technologies and accelerating engineering integration and securing related engineering technologies. Currently, the nation should focus on large-scale collection of large-scale collection of acquisitions in the near future. Based on the government-led large-scale demonstration project initiative and participation in international project projects, the groundwork for early commercialization of CCS technology and the initial opening of the CCS new project will be needed. It is necessary to establish a foundation for effective implementation of policies by strengthening cooperation among departments and establishing cooperative relationships among ministries and departments. Investment in investment efficiency and inducement of private companies to invest in private companies is also needed. The continued lack of sufficient investment due to the continued deterioration of the nation`s fiscal conditions will help spur the ongoing growth of the CCS technology. When these government efforts are sustained steadily from a long-term perspective, the nation will be able to achieve the goal of achieving national greenhouse gas reduction targets and emerge as a CCS power house in coping with climate change.

\section{ACKNOWLEDGEMENT}

This work is financially supported by Korea Ministry of Environment (MOE) as $\ulcorner$ Knowledge-based environmental service Human resource development Project $\lrcorner$.

\section{REFERENCES}

[1] Silent killer, PM2.5, Health Effects of Korea Coal thermal power plants and its current address, Green Peace.

[2] A study on the Goal of Long-term GHG Emissions Reduction in the Development Area, Energy Economics Research Institute, Ahn Jae-Kyun, 2016.

[3] Reducing GHG emissions in coal thermal power generation, Yoon Yong-seung.

[4] No.11 Dec 2015 KISTEP InI, Korea Institute of S\&T Evaluation and Planning(KISTEP)

[5] The concept of fine dust(fine dust, what is it?), Ministry of Environment, 2016.

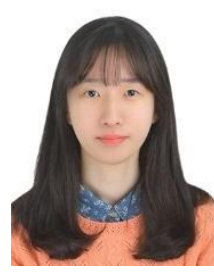

Ji Young Kim graduated from the Department of Environmental Engineering, Incheon National University, and she attends in the master's course of the Department of Environmental and Energy Engineering in Incheon National University.

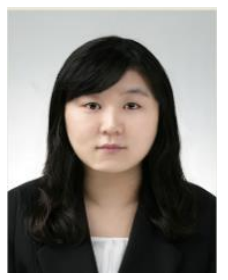

Hee Jung Kim graduated from the Department of Environmental Engineering, University of Incheon. She attends in Master's course of Dept. of Environment and Energy Engineering in Graduate School of Incheon National University.

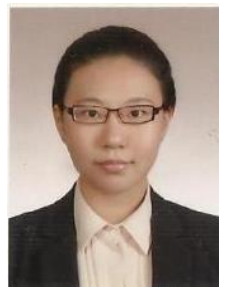

Ji Ye Yoo graduated from Incheon National University, and got the master degrees in same university. Her major fields of research are the air pollution control, greenhouse gas and odor management. She is now enrolled in a doctoral course at the Department of Climate International Cooperation, Incheon National University, Republic of Korea.

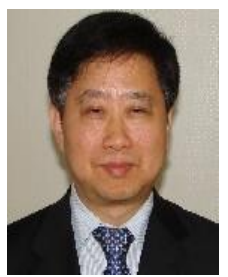

Prof. Chan Jin Park graduated from Korea University, and got the master and $\mathrm{PhD}$ degrees in same university. His major fields of research are the air pollution control, greenhouse gas technology and odor management technology. His another interests is green growth policy. He is now full-professor in Urban Science College of Incheon National University. 